\title{
KANTOR DIGITAL KREATIF STARTUP
}

\author{
Timothy ${ }^{1)}$, Mieke Choandi ${ }^{21}$ \\ 1)Program Studi S1 Arsitektur, Fakultas Teknik, Universitas Tarumanagara, sp_timothy@yahoo.com \\ 2) Program Studi S1 Arsitektur, Fakultas Teknik, Universitas Tarumanagara, miekec@ft.untar.ac.id
}

\begin{abstract}
Abstrak
Di era revolusi industri 4.0, teknologi digital sudah menjadi kebutuhan bagi para milenial. Melalui internet semua bisa saling terhubung satu dengan yang lain menjadikannya sebuah peluang bisnis baru yaitu startup. Kehadiran startup bisnis yang berbasis bisnis digital ini sekarang menjadi trend bisnis di kalangan milenial. Akan tetapi, membangun sebuah bisnis startup tidaklah mudah. Banyak bisnis startup yang jatuh bangun dalam menjalankan bisnisnya bahkan kalah bersaing dengan startup yang lebih besar. Kantor dengan sistem lama tidaklah sesuai dengan perilaku milenial dan bisnis startup ini yang lebih banyak membutuhkan ide-ide kreatif dan inovatif. Para milenial membutuhkan sebuah tempat bekerja dengan konsep baru dalam meningkatkan kreatifitas dan produktivitas mereka dalam bekerja. Pengusulan program "Kantor Digital Kreatif Startup" memiliki tujuan untuk menghadirkan program kantor dengan konsep yang baru untuk para milenial dalam menjalankan bisnis startup di era serba digital saat ini. Kantor bukan lagi sebagai tempat untuk bekerja saja melainkan tempat untuk mencari pengalaman, belajar hal baru, bersosialisasi dan berkomunitas. Milenial membutuhkan lingkungan kerja yang interaktif, santai, menyenangkan, fleksibel dan kolaboratif untuk mendukung performa produktivitas di dalam kantor. Dengan hadirnya kantor startup, diharapkan dapat meningkatkan perekonomian masyarakat terutama kaum milenial dalam berwirausaha melalui bisnis startup yang sedang berkembang.
\end{abstract}

Kata kunci: Digital; Kantor; Mileniall; Startup.

\begin{abstract}
In this industrial revolution 4.0 era, digital technology has become a necessity for millennials. Through the internet, everyone can be connected to each other making it a new business opportunity, namely startup. The presence of a startup business based on digital business is now a trend among millennials. However, building a startup business is not easy. Many startup businesses that are falling apart in running their businesses are even unable to compete with larger startup. Offices with old systems are no longer in accordance with millennial behaviors and this startup business needs more creative and innovative ideas. Millennials need a place to work with new concepts in increasing their creativity and productivity at work. The proposed program 'Creative Startup Digital Office' aims to present an office program with a new concept for millennials in running a startup business in today's digital era. The office is no longer just a place to work but a place to find experience, learn new things, socialize and community. Millennial requires an interactive, relaxed, fun, flexible and collaborative work environment to support productivity performance in the office. With the presence of this startup office, it is hoped that it will be able to improve the economy of the people especially millenials in entrepreneurship through a growing startup business.
\end{abstract}

Keywords: Digital; Office; Millenial; Startup.

\section{PENDAHULUAN}

Jumlah penduduk di Jakarta mencapai 10 juta jiwa yang tecatat dalam Badan Pusat Statistik Provinsi DKI Jakarta. Jakarta menjadi tujuan utama bagi masyarakat Indonesia untuk mengadu nasib sehingga tidak heran Jakarta semakin padat penduduk, bangunan serta tingkat kemacetan yang tinggi. Berdasarkan Survei Penduduk Antar Sensus (SUPAS) 2015 jumlah penduduk DKI Jakarta akan mencapai puncak tertingginya pada 2040, yakni 
mencapai 11,28 juta jiwa. Jumlah penduduk yang semakin bertambah dan tidak diikuti dengan jumlah lapangan pekerjaan yang seimbang maka akan menyebabkan tingginya angka pengangguran. Tingkat pengangguran dapat diatasi dengan berwirausaha. Dengan berwirausaha maka secara tidak langsung akan menghasilkan lapangan kerja yang baru.

Di zaman sekarang ini, generasi milenial hidup di era revolusi industri 4.0 dimana teknologi digital tumbuh dan berkembang menjadi pusat dari segala aktivitas seperti bekerja, belajar, berbelanja, bermain, dll. Revolusi industri 4.0 secara langsung dan tidak langsung mempengaruhi berbagai bidang industri untuk berkembang melalui teknologi digital dan internet, salah satunya adalah dalam perekonomian. Proses globalisasi dan konektivitas telah mengubah cara manusia dalam bertukar informasi, berniaga, konsumsi, bersosialisasi dan berbagai hal lainnya. Dunia menjadi tempat yang sangat dinamis dan kompleks sehingga kreativitas dan pengetahuan menjadi suatu aset yang tak ternilai dalam kompetisi dan pengembangan ekonomi. Ekonomi kreatif hadir sebagai solusi yang menempatkan kreativitas dan pengetahuan sebagai aset utama dalam menggerakkan ekonomi yang memunculkan sebuah pandangan baru dalam berusaha. Salah satu bidang industri ekonomi kreatif adalah startup.

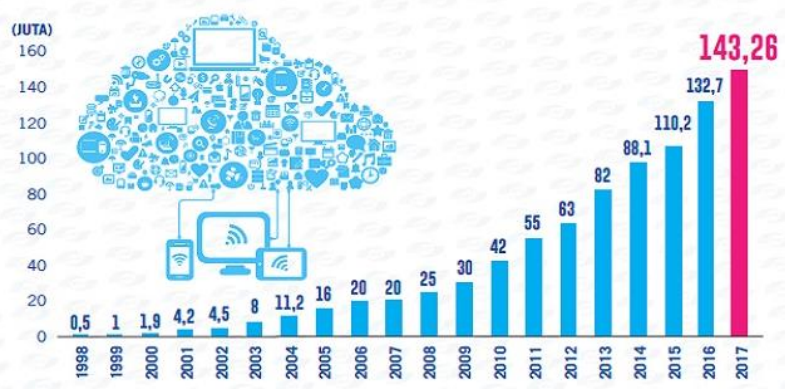

Gambar 1. Pertumbuhan Pengguna Internet di Indonesia (sumber : www.viva.com)

Startup adalah perusahaan berbasis teknologi digital yang baru berkembang seperti Gojek, Grab, Tokopedia, Bukalapak, dll. Pertumbuhan pengguna internet yang terus meningkat setiap tahunnya menjadikannya prospek yang baik dalam menjalankan bisnis startup. Startup bekerja dengan cara memecahkan suatu masalah menggunakan ide-ide atau memanfaatkan masalah itu sendiri sebagai ide bisnis sekaligus diberikan terobosan yang cukup revolusioner dengan membawa pengaruh besar pada komunitas di masyarakat. Bisnis startup merupakan langkah untuk berwirausaha secara digital dan online. Kehadiran bisnis startup yang berbasis digital ini sekarang menjadi trend bisnis di kalangan milenial. Akan tetapi, membangun sebuah bisnis startup tidaklah mudah, perlu adanya riset dan analisis yang cermat dalam menjangkau target pasar, produk, branding, dll. Banyak bisnis startup yang jatuh bangun dalam menjalankan bisnisnya.

Peran arsitektur dalam menanggapi isu tersebut adalah dengan menciptakan sebuah kantor yang dapat menjadi wadah dalam memulai, menjalankan dan mengembangkan bisnis startup tersebut. Wadah yang akan dikembangkan merupakan sebuah wadah kreatif yang mendukung kegiatan startup termasuk kegiatan komunitasnya seperti melakukan riset, workshop, pameran, dll. Diharapkan bisnis startup akan semakin maju bila memiliki lingkungan dan sistem yang mendukungnya.

\section{KAJIAN LITERATUR}

\section{Tinjauan Umum Kantor}

Pengertian Kantor Kantor berasal dari bahasa Belanda "Kantoor" adalah sebutan untuk tempat yang digunakan untuk perniagaan atau perusahaan yang dijalankan secara rutin. Kantor bisa hanya berupa suatu kamar atau ruangan kecil maupun bangunan bertingkat tinggi. Kantor menurut Kamus Besar Bahasa Indonesia (KBBI) adalah balai (gedung, rumah, atau ruang) tempat mengurus suatu pekerjaan atau juga disebut tempat bekerja. 
Menurut Mills (1978), tujuan kantor didefinisikan sebagai pemberian pelayanan komunikasi dan perekaman. Dari definisi tersebut, Mills memperluas menjadi fungsi kantor (pekerjaan yang dilakukan) yakni sebagai berikut:

a. Menerima Informasi (to receive information)

b. Merekam/ menyimpan data-data serta informasi (to record information)

c. Mengatur Informasi (to arrange information)

d. Memberi Informasi (to give information)

e. Melindungi Aset (to safeguard assets)

\section{Persyaratan Umum Kantor}

Tata ruang merupakan suatu metode untuk membenahi dan menyusun alat-alat dan perlengkapan dalam ruangan, yang bertujuan memberikan sarana bagi pekerja. Dengan mempertimbangkan persyaratan umum berikut ini (Harsono, 2004) :

a. Menggunakan segenap ruangan yang ada secara ekonomis, sehingga setiap bagian dari ruangan dapat bermanfaat.

b. Memudahkan pengawasan sehingga manajer dapat melihat staf yang sedang bekerja.

c. Memberikan kemudahan yang optimum bagi arus komunikasi dan arus kerja.

d. Memberikan kepuasan dan kenyamanan kerja.

e. Menyediakan pelayanan yang menyenangkan, seperti komputer, telepon, teleks, interkom, dan pelayanan lainnya yang menyangkut pelayanan rumah tangga perusahaan, seperti penyediaan air minum.

f. Memberikan kemudahan yang tinggi kepada setiap gerakan pegawai.

g. Menghindari kemungkinan dari saling mengganggu antara satu pegawai dengan pegawai lainnya.

h. Memberikan keleluasaan dan keamanan pribadi.

i. Memisahkan pekerjaan yang berbunyi keras, gaduh dan mengganggu dari pekerjaan yang membutuhkan konsentrasi.

j. Menciptakan citra baik perusahaan.

\section{Klasifikasi Kantor}

Secara garis besar jenis kantor dapat dibedakan menjadi 4 macam menurut (Manasseh \& Cunliffe, 1962), yaitu :

a. Commercial Office

Jenis perkantoran yang termasuk golongan ini adalah perkantoran (untuk took, disewakan), perusahaan (trading company), asuransi dan transportasi.

b. Industrial Office

Jenis perkantoran ini terikat hams mempunyai hubungan fisik dengan pabriknya.

c. Profesional Office

Jenis perkantoran ini tidak dipakai dalam waktu yang panjang dan merupakan perkantoran yang jumlah modal yang digunakan relative kecil.

d. Institutional / Governmental Office

Jenis perkantoran ini bersifat usaha yang teratur dalam bentuk lembaga. Biasanya digunakan dalam waktu yang lama atau panjang.

Berdasarkan tipe ruangannya, secara umum dapat dibedakan tiga jenis ruang yang terdapat di dalam kantor (wikipedia) :

a. Ruangan Kerja (Work Spaces)

Ruangan kerja dalam suatu kantor biasanya digunakan untuk melaksanakan pekerjaan kantor yang lazim, seperti membaca, menulis dan pekerjaan dengan computer. Ada sembilan jenis generik ruangan kerja, masing-masing mendukung aktivitas-aktivitas yang berbeda. 


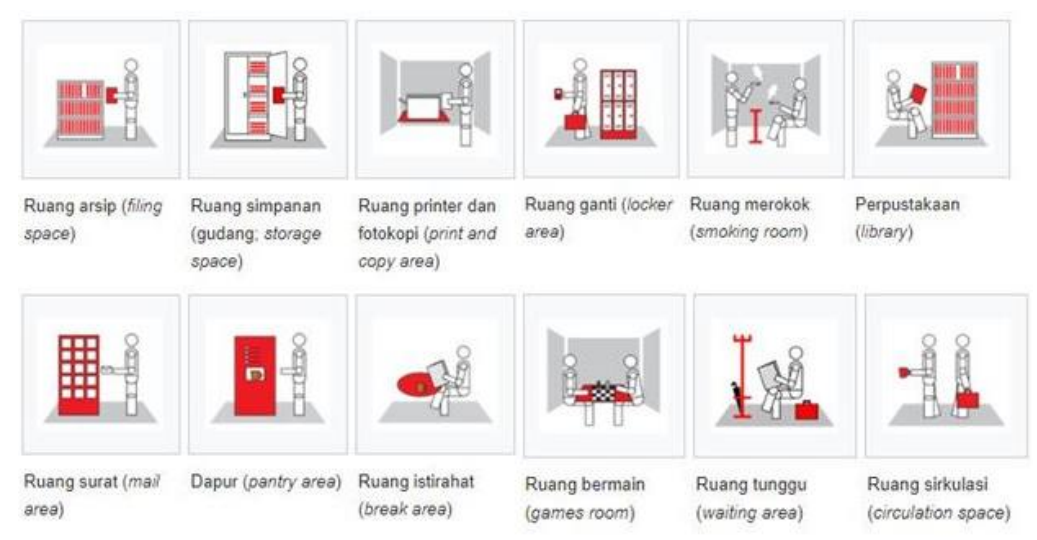

Gambar 3. Tipe Ruangan Kerja

(sumber : www.wikipedia.com)

b. Ruangan Pertemuan (Meeting Spaces)

Ruangan pertemuan dalam sebuah kantor biasanya digunakan untuk proses interaktif, dapat berupa percakapan singkat atau pertukaran pendapat brainstorm intensif. Ada enam jenis generik ruangan pertemuan dengan aktivitas-aktivitas yang berbeda.

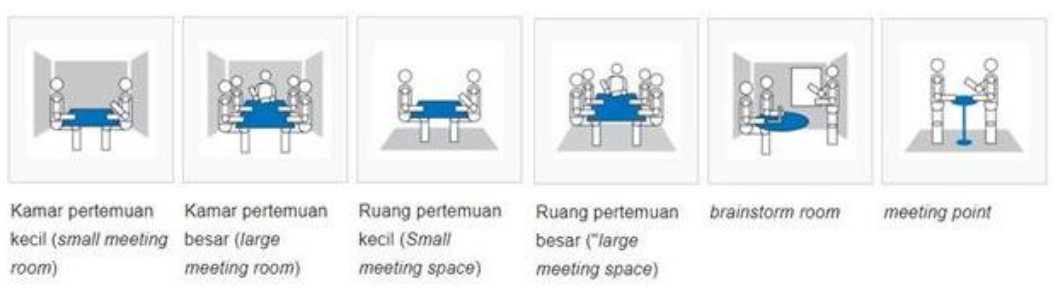

Gambar 4. Tipe Ruangan Pertemuan

(sumber : www.wikipedia.com)

c. Ruangan Pendukung (Support Spaces)

Ruangan pendukung dalam suatu kantor biasanya digunakan untuk aktivitas sekunder seperti pengarsipan dokumen atau beristirahat. Ada dua belas jenis generik ruangan pendukung dengan aktivitas-aktivitas yang berbeda.

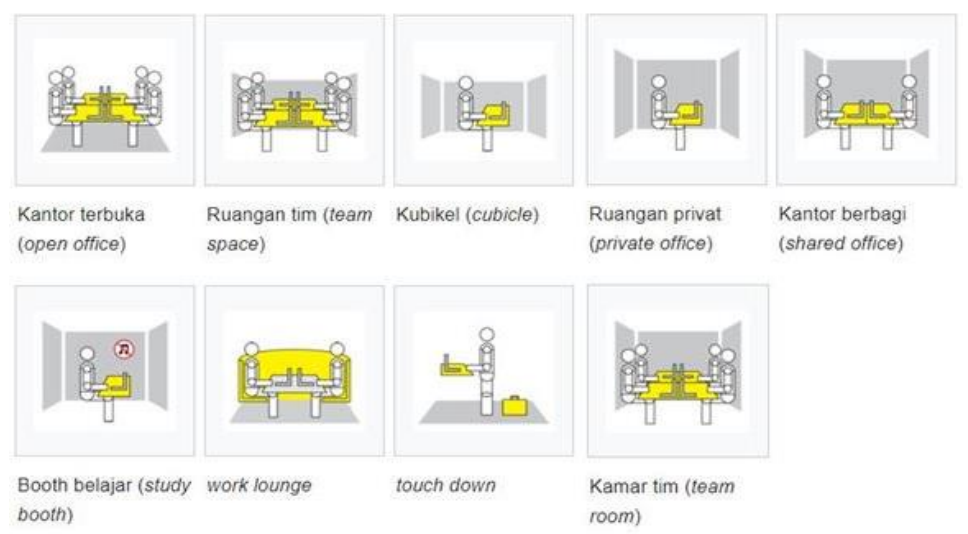

Gambar 5. Tipe Ruangan Pendukung

(sumber : www.wikipedia.com)

\section{Kebutuhan Aktivitas Kantor}

Aktivitas merupakan inti dari pengambilan keputusan mengenai sebuah tempat kerja, segala aktivitas memiliki baik kebutuhan fisik maupun psikologis. Beberapa aktivitas dapat mewakili kebutuhan yang sama dan dapat berjalan dengan baik dalam satu ruang ataupun berdampingan. Hanya dengan menganalisa secara menyuluruh kebutuhan ini dapat memberi ruang perencanaan yang efektif. Analisa aktivitas tersebut dapat digolongkan berdasarkan karakter mereka, yaitu: (Raymond and Cunliffe, 34) 

a. Creative
Brainstorming, Designing, Strategic Planning, Report Writing.
b. Persuasive
Negotiating, Presenting, Training, Selling.
c. Absorbing
Reading, Researching, Training, Selling.
d. Reflective
Greeting, Eating, Exercising.
e. Hmdrum
Word Processing, Filing, Photocopy, Checking.
f. $\quad$ Refreshing
Greeting, Eating, Exercising.
g. Informative
Actively Telling, Passive Overhearing.
h. Compassionate
Counseling, Helping.

\section{Faktor yang mempengaruhi Perilaku}

Perilaku manusia dan hubungannya dengan suatu setting fisik sebenarnya terdapat keterkaitan yang erat dan pengaruh timbal balik diantara setting tersebut dengan perilaku manusia. Dengan kata lain, apabila terdapat perubahan setting yang disesuaikan dengan suatu kegiatan, maka akan ada imbas atau pengaruh terhadap perilaku manusia. Faktor-faktor yang berpengaruh terhadap perilaku manusia (Setiawan, 1995), antara lain :

a. Ruang

Hal terpenting dari pengaruh ruang terhadap perilaku manusia adalah fungsi dan pemakaian ruang tersebut. Perancangan fisik ruang memiliki variable yang berpengaruh terhadap perilaku pemakainya.

b. Ukuran dan bentuk

Ukuran dan bentuk ruang harus disesuaikan dengan fungsi yang akan diwadahi, ukuran yang terlalu besar atau kecil akan mempengaruhi psikologis pemakainya.

c. Perabot dan penataannya

Bentuk penataan perabot harus disesuaikan dengan sifat dari kegiatan yang ada di ruang tersebut.

d. Warna

Warna memiliki peranan penting dalam mewujudkan suasana ruang dan mendukung terwujudnya perilaku-perilaku tertentu. Pada ruang, pengaruh warna tidak hanya menimbulkan suasana panas atau dingin, tetapi warna juga dapat mempengaruhi kualitas ruang tersebut.

e. Suara, Temperatur dan Pencahayaan

Suara, temperatur dan pencahayaan harus diatus sedemikian sesuai kegiatan dan ruangannya karena dapat mempengaruhi psikologis seseorang.

\section{Generasi Milenial}

Pengelompokan generasi menurut Brosdahl dan Carpenter (2011) dibagi menjadi enam, yaitu :

- Generasi WWII

(1901-1924)

- Generasi Silent

- Generasi Baby Boomer (1946-1964)

- Generasi X

- Generasi Millenial

- Generasi Z (2003-) 
Generasi millenial atau sering disebut generasi $Y$ merupakan generasi pertama yang menghabiskan seluruh hidup mereka pada lingkungan digital, yang tentu saja berimplikasi pada bagaimana cara mereka hidup dan bekerja (Bennett et al, 2008, Wessner and Miller, 2008). Menurut beberapa penelitian, generasi ini disebut greatest generation (Howe \& Strauss, 2000).

Generasi millenial diantaranya ditandai dengan karakteristik sebagai berikut :

a) Digital Immersion

Generasi millenial tidak hanya nyaman dengan menggunakan teknologi, teknologi adalah bagian yang terintegrasi dengan generasi millenial. Teknologi dan perkembangannya tersebut sangat berpengaruh untuk generasi ini (Tapscott, 2009).

b) Mentalitas Open Source

Kekuatan dari generasi millenial berasal dari pengaruh facebook, twitter, wikipedia, dan media sosial lain yang memiliki pengaruh dalam membentuk perdagangan, politik, pendidikan, dan struktur sosial. Bentuk baru dalam berkomunikasi dalam pengiriman pesan dengan menyingkat pesan yang disampaikan. Berdasarkan pengalaman mereka, generasi millenial memiliki asumsi bahwa semua informasi penting dapat dikumpulkan dengan sentuhan tangan atau melalui gadget (Hershatter \& Epstein, 2010).

c) Content Creation

Generasi millenial tidak pernah puas hanya dengan mendapatkan dan menggunakan informasi; mereka juga akan mencari cara untuk membuat informasi melalui blog, media interaktif, twitter, dan media sosial lainnya (Jones \& Fox, 2009). Membagikan informasi lewat blog adalah salah satu contoh yang membuktikan bahwa generasi millenial ingin menangkap, mengorganisasikan, dan menyebarkan pemikiran, opini, dan pengalaman mereka (Hershatter \& Eppstein, 2010).

d) Menyukai Fleksibilitas

Generasi millenial adalah generasi yang meyukai fleksibilitas kerja dan karir. Selanjutnya, sebagai digital native, generasi millenial percaya bahwa mereka dapat bekerja dengan lebih efisien dengan memanfaatkan teknologi, contohnya adalah menghilangkan waktu untuk halhal yang tidak perlu, non-esensial, interaksi tatap muka yang terjadi dalam pengaturan kantor pada umumnya (Erickson, 2008:177).

\section{METODE}

Dalam perancangan ini, perancang menggunakan dua metode utama untuk menjawab permasalahan dan mencapai tujuan dari perancangan ini, yaitu

a. Studi Literatur, mengenal dan mengetahui tentang teori yang didapat dari buku-buku baik dari segi filosofi, arsitektur maupun yang lainnya serta dari media elektronik seperti instagram, pinterest, issue dan lain sebagainya.

b. Studi kasus, dilakukan dengan pengamatan terlebih dahulu terhadap objek yang berkaitan dengan tema penulisan dan survey lapangan atau observasi.

\section{DISKUSI DAN HASIL}

Dari hasil penelitian dapat dikatakan bahwa tingkat produktifitas milenial dalam bekerja sangat bergantung pada sistem kerja dan desain ruang yang dihasilkan. Sistem kerja kantor konvensional yang memiliki struktur hirarki, alur kerja yang monoton, kurangnya interaksi dan kolaborasi antar pekerja, lingkungan kerja yang tidak fleksibel (cubicles) menciptakan suasana yang tidak kondusif bagi milenial dalam bekerja. Sistem kantor lama sudah tidak lagi kontekstual terhadap perilaku milenial saat ini. Pentingnya unsur kolaborasi, fleksibilitas, interaksi dan kreativitas dalam bekerja menjadi hal yang harus diperhatikan dalam mendesain kantor milenial terutama kantor startup. Maka dari itu beberapa kegiatan kantor harus dapat menciptakan sebuah citra kolaboratif, fleksibel dan mempunyai wadah untuk berkembang. 

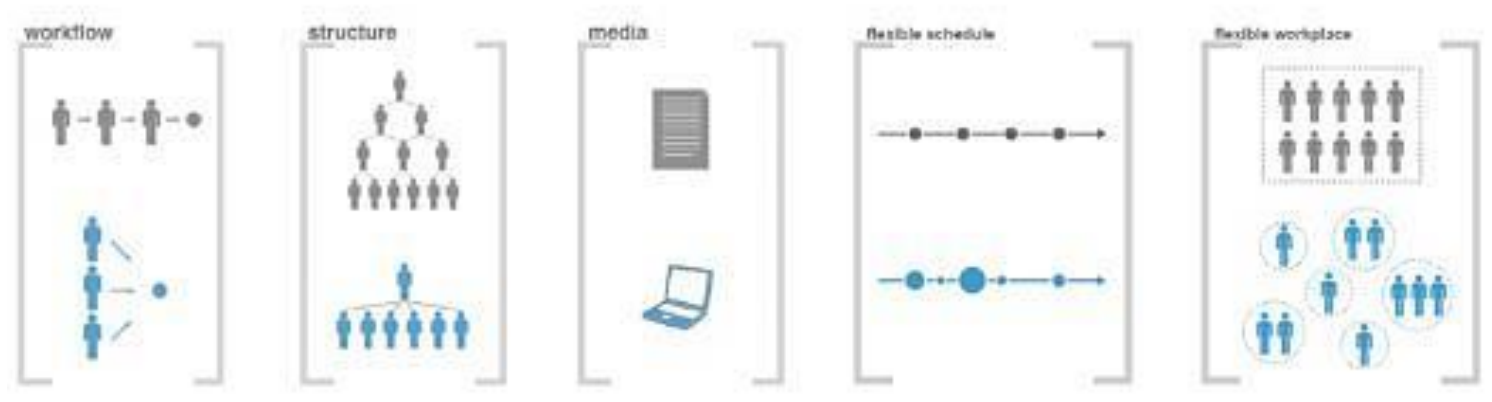

Gambar 5. Sistem Kantor Startup Facebook (sumber : https://surface.syr.edu)

Program yang disajikan pada proyek ini berupa community office dimana menggabungkan program kantor dan komunitas. Konsep Trans-proggramming ini memungkinkan pengguna bekerja dan berkomunitas. Fungsi program bertujuan untuk meningkatkan kegiatan kolaborasi dan interaksi, mengenalkan bisnis startup dan teknologi digital, mengubah sistem kantor menjadi lebih interaktif, menciptakan lingkungan kantor startup yang terbuka terhadap sekitar dan meningkatkan kegiatan bisnis komersial di dalam kantor.

\section{Analisis}

Jakarta Selatan merupakan salah satu daerah Jakarta yang menjadi pusat perkantoran. Kawasan strategis yang berada dekat dengan pusat kota serta dilengkapi dengan fasilitas transportasi umum dan pedestrian yang memadai serta akses kendaraan yang mudah dijangkau dengan jalan tol menjadikan kawasan ini menjadi favorit untuk dijadikan kawasan bisnis terutama bisnis startup. Persebaran perusahaan Startup di Jakarta masih berpusat pada pusat daerah bisnis di Jakarta Selatan khususnya daerah Kuningan, Slipi dan Sudirman. Belum adanya pusat distrik berbasis teknologi di Jakarta seperti di Silicon Valley, Amerika serikat maka perusahaan startup cenderung berpusat pada lokasi bisnis yang strategis baik dalam akses, pencapaian, fasilitas, target pasar dll.

\section{Kriteria pemilihan tapak:}

- Mempunyai akses pencapaian yang mudah baik transportasi umum, kendaraan dan pejalan kaki dengan jangkauan kota.

- Dekat dengan pusat kota sebagai daerah pusat bisnis startup yang dapat mendukung kegiatan komunitas bisnisnya. 


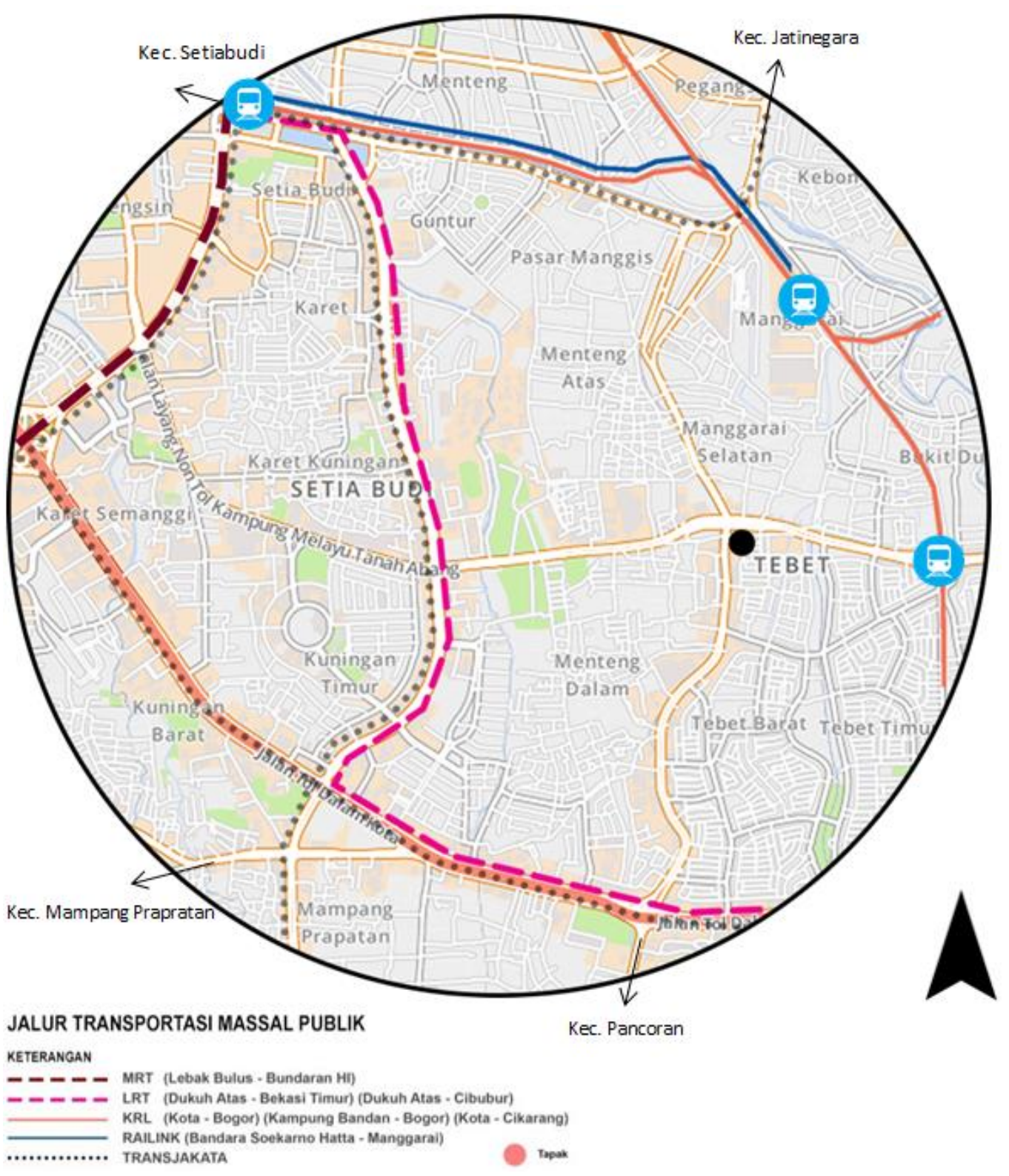

Gambar 6. Peta Jalur Transportasi Publik

Sumber: Penulis, 2019

Kawasan Tebet memiliki potensi sebagai pusat bisnis sekunder seiring dengan berkembangnya transportasi publik seperti MRT dan LRT di kawasan Sudirman. Lahan yang semakin lama semakin sedikit di kawasan CBD Kuningan dan Sudirman menjadikan kawasan Tebet sebagai ekspansi daerah bisnis strategis di masa yang akan datang. Kawasan Tebet juga mempunyai akses kendaraan yang mudah dengan dilintasi dengan Jalan Arteri Sekunder yang terhubung dengan Jalan Arteri Primer. Berdasarkan RDTR 2030, kawasan Tebet didominasi oleh hunian dan perkantoran pada sisi-sisi tepi Jalan Arteri Sekunder sehingga banyak berkembangnya fasilitas pendukung hunian seperti tempat kuliner, sekolah masjid, universitas, rumah sakit, dll. Kawasan Tebet didominasi dengan bangunan rendah 1-4 It sedangkan bangunan tinggi 20-40 It berada di sekitar flyover. Dilihat dari struktur kotanya, kegiatan dan aktivitas perdagangan berkembang secara linear mengikuti Jalan Arteri Sekunder terdapat hotel, apartemen, mall, kantor dll. Bangunan sekitar flyover menjadi vocal point yang dapat dimaksimalkan sebagai daya tarik. 


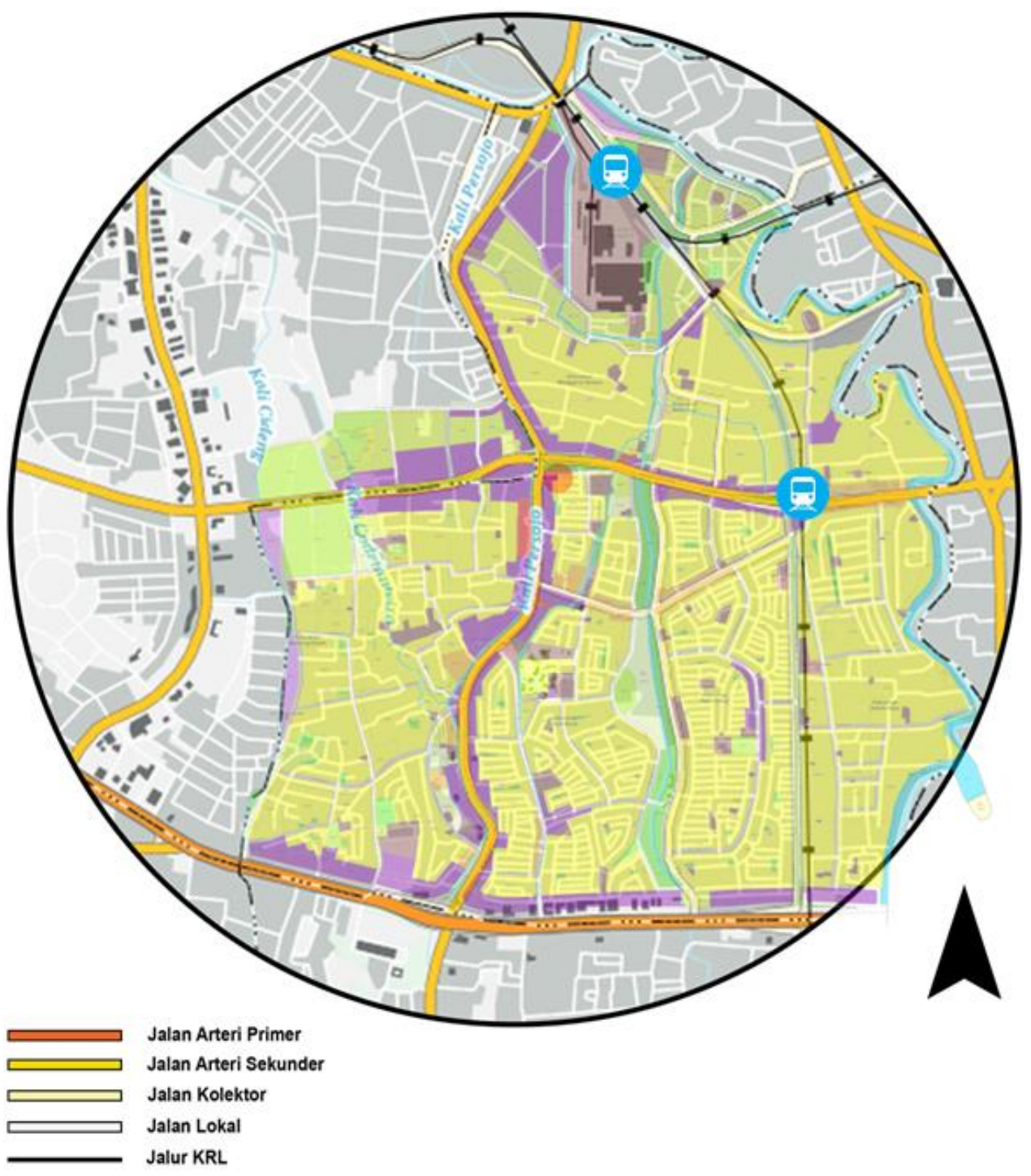

Gambar 7. Peta Klasifikasi Jalan dan Tata Guna Lahan

Sumber: Penulis, 2019

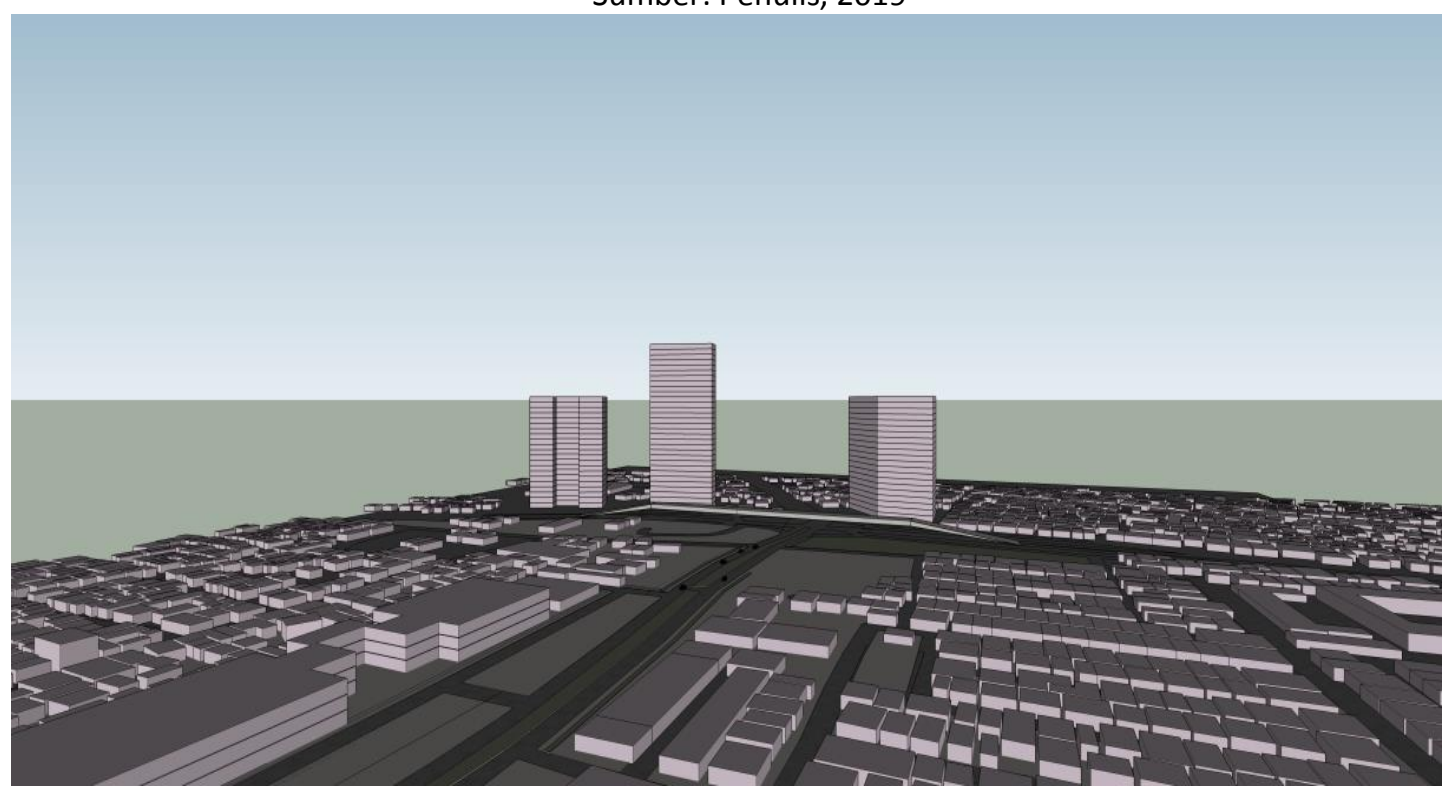

Gambar 8. Pemetaan Ketinggian Bangunan

Sumber: Penulis, 2019 


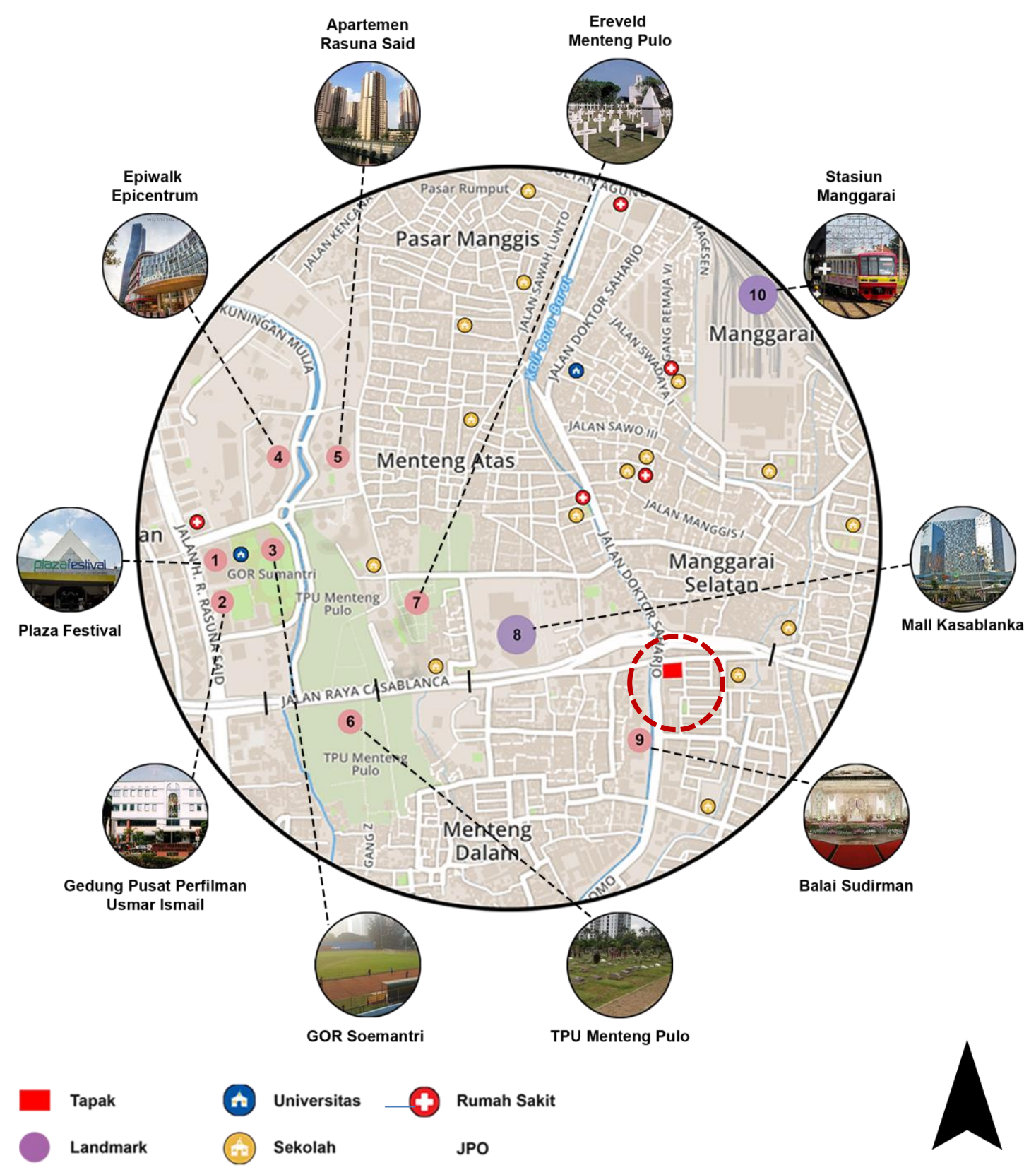

Gambar 9. Pemetaan Sarana dan Fasilitas Kawasan Tebet Sumber: Penulis, 2019

\begin{tabular}{|c|c|}
\hline $\begin{array}{l}\text { STRENGTH } \\
\text { - Berada di kawasan dengan transportasi publik yang lengkap } \\
\text { seperti KRL, MRT, LRT, Transjakarta, dll } \\
\text { - Lokasi strategis yang berdekatan dengan CBD Kuningan } \\
\text { sebagai pusat sentra bisnis primer } \\
\text { - Mempunyai kemudahan akses kendaraan melalui Jakarta } \\
\text { Inner Ring Road }\end{array}$ & $\begin{array}{l}\text { WEAKNESS } \\
\text { - Tingkat kebisingan yang tinggi dari kendaraan } \\
\text { - Kawasan rawan kemacetan } \\
\text { - Kurangnya area terbuka hijau, padat bangunan }\end{array}$ \\
\hline $\begin{array}{l}\text { OPPORTUNITY } \\
\text { - Kawasan strategis yang memiliki potensi sebagai pusat bisnis } \\
\text { sekunder setelah CBD Kuningan } \\
\text { - Mempunyai akses yang mudah dengan pusat bisnis di sekitar } \\
\text { - Memiliki potensi untuk menjadi tempat komunitas } \\
\text { entrepreneur startup }\end{array}$ & $\begin{array}{l}\text { THREAT } \\
\text { - Harga tanah sangat mahal dengan kisaran } \\
\text { harga lebih dari } 10 \text { juta/m² } \\
\text { - Jalur pedestrian di beberapa titik menuju tapak } \\
\text { masih kurang memenuhi standard rencana } \\
\text { RDTR } 2030\end{array}$ \\
\hline
\end{tabular}




\section{Konsep}

Pada tahap Seed, menawarkan kegiatan yang memberikan wawasan, pengalaman dan kegiatan pengenalan kepada publik mengenai startup dan teknologi digital yang berkembang dalam bentuk event startup, talkshow, seminar, pameran dan bazaar. Pada tahap Early, merupakan program kegiatan lanjutan yang merupakan kegiatan pembelajaran mengenai startup dalam bentuk workshop dan incubator. Pada tahap Growth, merupakan program yang memberikan wadah dan fasilitas untuk para wirausaha startup dalam mengembangkan bisnis startup mereka.

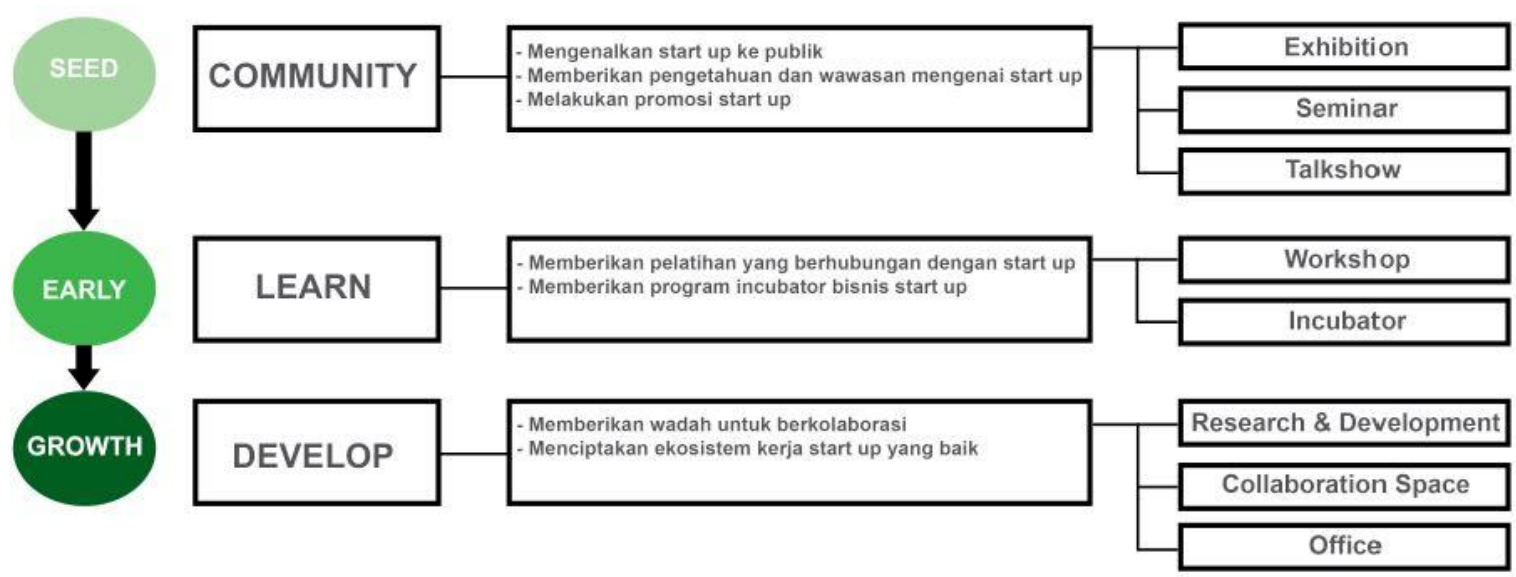

Gambar 11. Program Aktivitas

Sumber: Penulis, 2019

Konsep kantor startup dibuat berdasarkan kebutuhan dan perilaku milenial dalam bekerja dengan trans-proggraming yaitu menggabungkan program kantor dan komunitas menjadi satu kesatuan program yang dapat berjalan bersamaan walaupun memiliki fungsi yang berbeda. Kantor sebagai tempat bekerja (privat) sedangkan komunitas sebagai tempat bersosialisasi dan kolaborasi (publik).

\section{OFFICE}
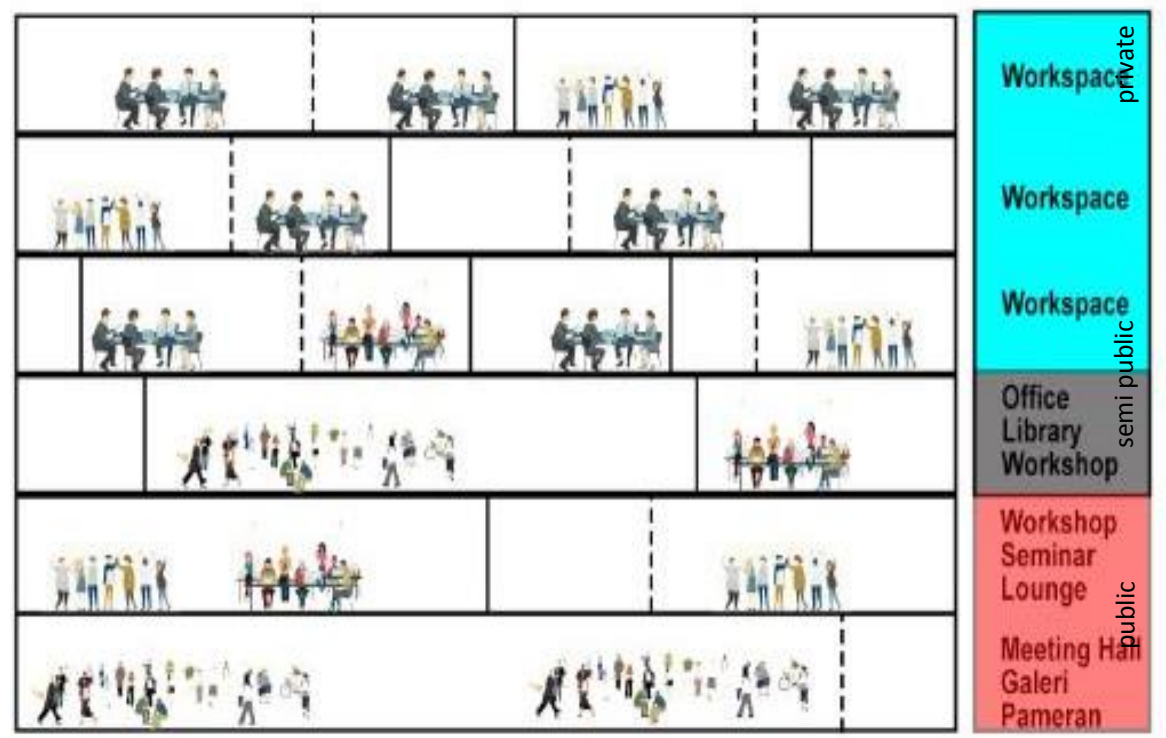

Gambar 12. Konsep Trans-Programming Sumber: Penulis, 2019 
Pembentukan massa dimulai dengan mengikuti bentuk tapak untuk kemudian diletakkan core inti bangunan sebagai area servis dan pencapaian vertikal (lift, tangga kebakaran). Core bangunan diletakkan di tengah berdasarkan efisiensi pencapaian dan sirkulasi. Melihat potensi keterhubungan tapak dengan taman di seberangnya, tapak kemudian dibagi menjadi 2 sirkulasi yaitu pejalan kaki dan kendaraan. Sirkulasi entrance kendaraan diletakkan pada area sisi kanan bangunan agar tidak terjadi crossing antara pejalan kaki dan kendaraan. Sedangkan sirkulasi entrance pejalan kaki di hadapkan langsung dengan taman.

Massa bangunan dipotong sebagian pada bagian hook dekat jalan utama sebagai vocal point yang memberikan kesan terbuka yang mengundang dan menarik perhatian publik. Area vocal point dibuat plaza terbuka dan menjadi akses masuk utama pedestrian. Massa bangunan dipotong pada bagian ujung bangunan di beberapa lantainya untuk membentuk ruang breakout outdoor sebagai area bersantai outdoor.

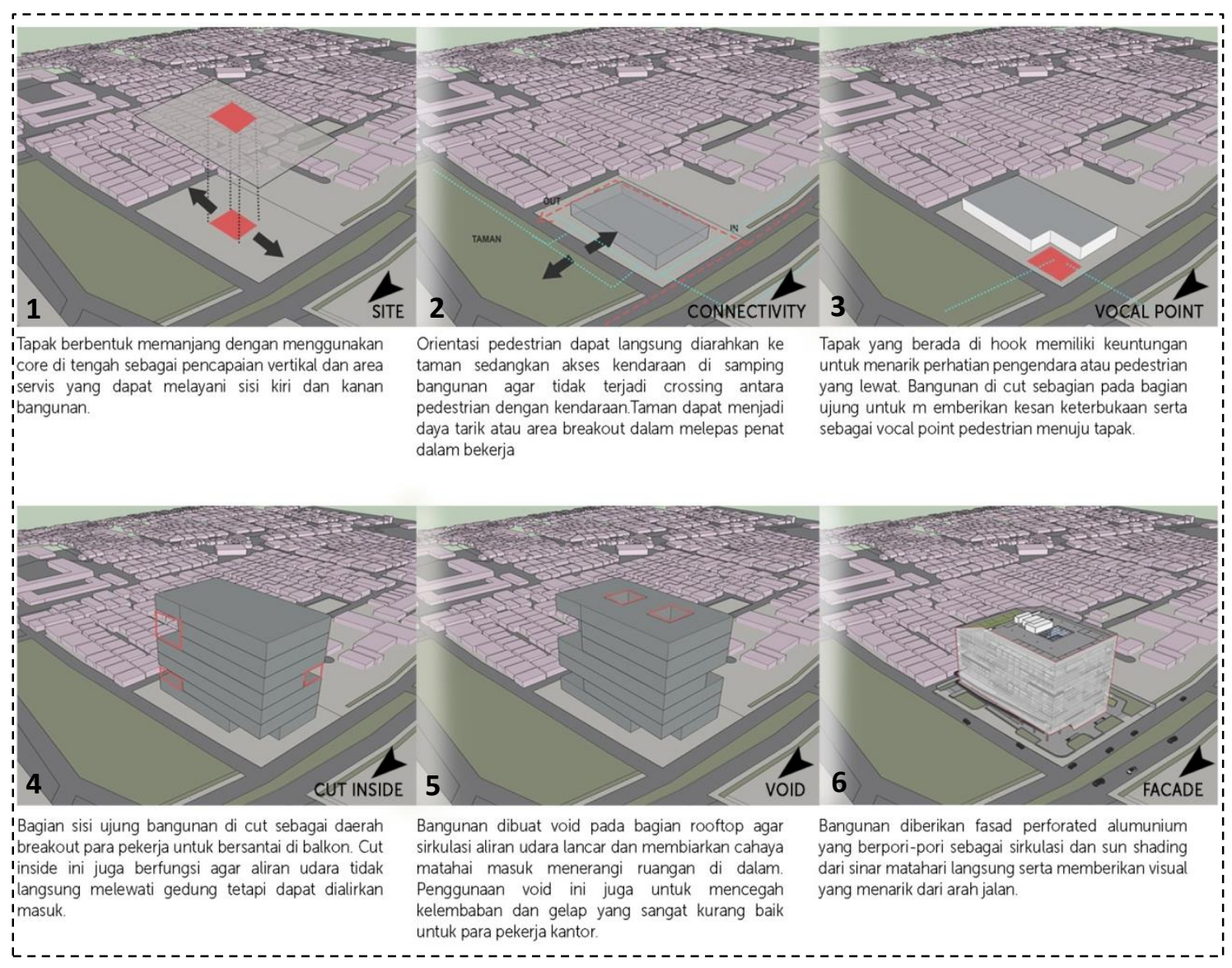

Gambar 13. Proses Gubahan Massa

Sumber: Penulis, 2019

Pembentukkan void pada bagian tengah bangunan dibuat agar cahaya dan udara dapat masuk ke dalam. Fasad bangunan dibuat dengan second skin agar terhidar dari sinar matahari langsung dan mengurangi tingkat radiasi matahari di dalam ruangan yang menyebabkan ruangan lebih panas. Second skin menggunakan material perforated alumunium yang dapat mengurangi sinar matahari yang masuk dan mengalirkan udara masuk melalui fasad. Material fasad juga dibuat dengan panel LED yang dapat digunakan sebagai atraksi di malam hari yang dapat menjadi daya tarik. 


\section{KESIMPULAN DAN SARAN}

Berkembangnya teknologi digital membuat banyak sekali perubahan dalam berbagai sektor. Salah satunya satunya adalah sektor eknomi. Bergantinya sebuah zaman juga mengubah revolusi industri ekonominya. Revolusi indstri kita sudah bergeser dari revolusi industri 3.0 menjadi revoulis industri 4.0. Revolusi industri 4.0 sekarang ini adalah revolusi industri yang bergerak dalam bidang Cyber Physical System atau sistem yang menggabungkan teknologi otomtisasi dengan cyber. Hadirnya revolusi industri 4.0 ini melahirkan konsep ekonomi kreatif yang berbasis bisnis teknologi digital yaitu "Startup". Startup merupakan bisnis yang bergerak dalam bidang teknologi digital. Startup ini menjadi trend di kalangan generasi milenial. Bisnis ini lebih mempunyai prospek berkembang yang lebih cepat dibandingkan mendirikan sebuah perusahaan. Fleksibilitas dan penggunaan modal yang lebih kecil menjadi pilihan utama generasi milenial dalam berbisnis.

Kota Jakarta sebagai kota metropolis juga perlu ikut berkembang dalam melihat potensi bisnis startup ini di kalangan milenial ini untuk mendorong ekonomi kreatif dalam upaya memajukan kota di masa depan. Oleh karena itu, kota membutuhkan wadah dalam mengembangkan potensi bisnis startup ini di kalangan milenial yang mampu mendorong para generasi milenial ini untuk menjadi entrepreneuer bukan hanya pekerja biasa.

Program proyek yang diusulkan untuk memenuhi isu permasalahan tersebut adalah sebuah Kantor Digital Kreatif Startup yang menjadi wadah pengembangan kreativitas dan bisnis startup dalam berbagai bidang. Program yang diusulkan adalah workshop, exhibition, coworking space, research center serta ruang pendukung lainnya seperti restaurant, cafe, toko komersial, perpustakaan, dll. Pembangunan proyek ini diharapkan dapat menjadi solusi dalam menjawab perkembangan zaman di era digital ini dengan menciptakan sebuah ekosistem bisnis startup yang baik serta mendorong para milenial untuk berkarya dan berkreativitas serta memiliki semangat entrepreneuership dalam meningkatkan perekonomian kota di masa depan.

\section{REFERENSI}

Erickson, T..J. (2008). Plugged In The Generation Y Guide to Thriving at Work. Harvard Business Press: Boston.

Harsono, dkk. (2004). Administrsi Perkantoran 1. Bandung: Alqaprint.

Haryadi dan Setiawan. (1995). Arsitektur Lingkungan dan Perilaku. Direktorat Jenderal Pendidikan Tinggi, Departemen Pendidikan dan Kebudayaan.

Haotian, L. (2012). Distributed Workplace for Facebook. Inc: a new office typology for the 21st century workstyle. diunduh 16 Januari 2019, < https://surface.syr.edu>

Hershatter, A. and Epstein, M. (2010). Millenials and the World of Work: An Organization and Management Perspective. Journal of Business Psychology

Manasseh, L. dan Cunliffe, R. (1962). Office Buildings. New York: Reinhold Publishing, Corp.

Marlina. E. (2008), Panduan Perancangan Bangunan Komersial. Andi Offset, Yogyakarta.

Mills, G. T. dan Standingford, O. (1978). Office Organization and Method. London: Pitman Publishing, Ltd.

Mills, G., dkk. (2007). Manajemen Perkantoran Modern. Jakarta: Binarupa Aksara.

Santa, R., Roger, C. (1997). Tomorrow's Office, Creating Effective and Humane Interior. London and New York.

Tapscott, D. (2009). Grown Up Digital: How the Net Generation is Changing Your World. New York: McGraw-Hill.

Van Meel, J. (2000). The European Office. 010 Publishers. 
